\title{
Shifting perceptions of consequences of IPV among beneficiaries of Indashyikirwa: An IPV prevention programme in Rwanda
}

\section{Erin Stern, Lea Liliane Niyibizi}

\begin{abstract}
$\underline{\text { Abstract }}$
Indashyikirwa is a Rwandan programme that seeks to prevent intimate partner violence (IPV) and support healthy, equitable relationships. A fundamental programme aspect is a 5 -month curriculum among heterosexual couples designed to identify the causes and consequences of economic, emotional, physical, and sexual IPV, and build skills to manage triggers of IPV. The programme also trained opinion leaders to more effectively prevent and respond to IPV, and established women's safe spaces to educate women about their rights, and accompany women who wish to report abuse or seek services. Drawing on 30 interviews with couples and 9 interviews with opinion leaders before and after completing the Indashyikirwa trainings, this paper highlights beneficiaries' perceived consequences of IPV, and how such perceptions were influenced through the Indashyikirwa programme. Interviews were conducted in Kinyarwanda, recorded, translated and transcribed into English and analyzed thematically. The data reveals a depth of understanding of consequences of various forms of IPV. Although several participants justified more minor forms of men's physical IPV, such as slapping, severe consequences of physical IPV were most readily identified and sanctioned. Various harms of emotional and economic IPV were reported, yet these forms of IPV were typically less socially sanctioned or identified as IPV. Conceptions of sexual IPV were influenced by inequitable gender norms, and not typically recognized as a violation under the law. Although the data does not yet demonstrate the long-term impact, collectively identifying the overlapping consequences and underlying power inequalities for all forms of IPV, the legal rights protecting against various forms of IPV, and the benefits of non-violent, equitable relationships, appeared to be helpful to shift perceptions of consequences of IPV. Implications of the findings for the programme and broader IPV prevention are identified.
\end{abstract}

\section{Introduction}

Intimate partner violence (IPV), which includes physical or sexual forms of violence, as well as psychological and economic abuse within intimate relationships (Buzawa \& Buzawa, 2013), is the most common form of violence against women, with $30 \%$ of women globally having experienced sexual and/or physical IPV during their lifetime (Devries et al. 2013). IPV can lead to a plethora of negative consequences; it is associated with women's greater rates of physical and emotional stress, depression, anxiety and 
suicide (Ellsberg et al., 2008), post-traumatic stress disorder (Goodwin, Chandler, \& Meisel, 2003) drug and alcohol abuse (Devries et al., 2014), serious injuries and death. Being a victim of sexual violence can make women more susceptible to adopting sexually risky behaviors, including having multiple partners, engaging in unprotected sex, and participating in transactional sex, thus exacerbating their risk of acquiring STIs including HIV (Abramsky et al., 2012). IPV can also be associated with increased STI risk for women as men who abuse their partners are more likely to exhibit riskier sexual behaviors (Silverman et al., 2008). Studies, particularly in the United States, have demonstrated how IPV can constrain women's capacity to find employment, lead to higher levels of absenteeism and job turnover, lower earning capacity and more limited occupational mobility (Goodwiner, Chandler \& Meisel, 2004; Swanberg, Logan \& Macke, 2005).

Although IPV interventions have traditionally emphasized responses to such violence including establishing support services for victims and improving the criminal and health sector responses (Abramsky et al., 2012), there has been a recent emphasis on interventions that prevent IPV. One promising IPV prevention approach is participatory group education to support individuals to identify the risk factors and consequences of IPV, and gain self-efficacy to prevent and respond to IPV (Campbell et al., 2013). Drawing on Friere's (1973) concept of 'critical consciousness,' individuals are encouraged to interrogate gender and social norms that underlie IPV and develop alternative norms promoting non-violence. Such gender transformative educational approaches including Stepping Stones, Program H, Men as Partners, have promisingly reported changes in attitudes related to IPV and in self-reported use of IPV (Jewkes et al., 
2008; Slegh et al., 2013). Attitudes towards IPV are critical to address as acceptance of IPV can hinder women's reporting or leaving a violent relationship (Mannell, Jackson, \& Umutoni, 2015), and help justify and maintain ongoing abuse in relationships. This paper reviews how a curriculum with couples and opinion leaders, which sought to raise awareness of the diverse consequences of IPV while simultaneously promoting the benefits of equitable, non-violent intimate relationships, influenced beneficiaries' perceptions of IPV including associated costs and consequences.

\section{Rwandan Context of IPV}

The last few decades in Rwanda has witnessed a significant growth of policies, laws and programmes supporting women's rights, some of which are intended to better prevent and respond to IPV. In 1999, the Law on Matrimonial Regimes, Liberalities and Successions established women's right to inherit land for the first time in Rwanda, including divorced women to ensure they do not become landless (Debusscher \& Ansoms, 2013). In 2008, the Rwandan government adopted the Prevention and Punishment of Gender Based Violence Law, which includes all forms of violence with the minimum penalty being six months in prison, while sexual abuse or rape leading to terminal illness or death can generate a life imprisonment sentence (Umubyeyi et al., 2014). As of 2012, the Rwandan penal code criminalized marital rape, which can result in imprisonment and fines (Umubyeyi et al., 2016). The Rwandan government has supported the development of various initiatives to tackle gender based violence (GBV) including IPV such as prevention clubs in schools and universities; prevention committees at the village level and parents' evening forums to raise awareness, identify, 
and assist victims of violence; and GBV desks at the Ministry of Defense and National Police (Slegh \& Kimonyo, 2010). In 2009, the Rwanda National Police and Ministry of Health launched the One Stop Centers, which offer free medical care, psycho-social support, and legal services to victims of IPV and child abuse, and emergency accommodation for a few days (Umubyeyi et al., 2016).

Yet, IPV in Rwanda is a persistent phenomenon with an estimated $20.7 \%$ of women aged 15-49 having experience physical or sexual violence by any husband/partner in the past 12 months, and $40 \%$ of ever married women having ever experienced any form of emotional, physical and/or sexual violence by their intimate partner (DHS, 2015). According to the 2014/2015 Rwanda DHS, acceptability of IPV was strongly correlated to IPV, with $53 \%$ of women who agreed with all five reasons justifying wife beating having experienced spousal physical, sexual or emotional violence. Women were most likely to agree a man is justified to beat his wife if she neglects the children (29\%), refuses to have sexual intercourse with him (24\%), or goes out without telling him $(22 \%)$, and in some circumstances, were more likely to agree with such justifications than men (DHS, 2015). Women's acceptance of IPV may reflect substantial gender power imbalances (Alio et al., 2014) and can prevent women from reporting IPV (Rani, Bonu, \& Diop-Sidibe, 2004; Mannell, Jackson, \& Umutoni, 2015). Other identified barriers to Rwandan women reporting IPV are fear of retaliation from their partner, humiliation, shame, and financial dependency on their partner (Kubai \& Alhberg, 2013; Mannell, Jackson, \& Umutoni, 2015; Umubyeyi et al., 2016). Only legally married women are guaranteed rights to property and custody in the case of divorce, which can hinder the ability of informally married women to leave abusive relationships (Powley, 2007). 
The government's various interventions to address IPV have been critiqued for emphasizing safety and empowerment of women, with insufficient attention to the root causes of IPV such as gender equitable norms (Slegh \& Kimonyo, 2010; Debusscher \& Ansoms, 2013). This includes concerns with Rwanda's GBV law for being strongly punishment oriented, inadequately promoting rights individuals possess under the law, or emphasizing how IPV is a form of gender discrimination (Herbert, 2015). Some identified norms underlying IPV in Rwanda are consideration of sexual violence as a private matter, men's perceptions of their right to always have sex with their wives, and the virtue for wives to silently endure certain forms of abuse, such as if their life is not threatened (Uwineza \& Pearson, 2009; Umubyeyi et al., 2014). When there are known cases of IPV, Rwandan cultural values encourage family or local leaders to firstly promote reconciliation among the couple, whereby divorce is the final alternative (Umubyeyi et al., 2014). A relatively unique aspect of the Rwandan government is its ability and willingness to promote gender equality and prevention of GBV, disseminate and hold citizens accountable to the related policies and laws. The country has decentralized, strong administrative mechanisms for ensuring implementation of policies and laws including performance contracts, which make public officials accountable to specific targets and timelines (Sommers, 2012). This is the context in which the Indashyikirwa programme works, which we turn to now.

\section{The Indashyikirwa Programme}

This paper draws on baseline and midline qualitative research undertaken to inform the evaluation of the Indashyikirwa programme, which aims to reduce IPV and support 
equitable, healthy relationships in Rwanda. The research presented is part of a broader evaluation of Indashyikirwa, which includes an RCT of couples trained and communities exposed to Indashyikirwa activities, and has a primary objective of whether the programme reduces men's perpetration and women's experiences of IPV. Indashyikirwa (meaning agents of change in Kinyarwanda) is a 4 year programme (2014-2018), funded by DFID Rwanda and being implemented by CARE International Rwanda, Rwanda Women's Network (RWN) and Rwanda Men's Resource Centre (RWAMREC) across 7 districts, and 14 sectors, in Eastern, Western and Northern provinces of Rwanda. A fundamental aspect of the programme is a 5-month curriculum among heterosexual couples aged 18 to 49 who were either legally married or lived together for at least 6 months, and with at least one partner being an active member of CARE's micro-finance village savings and loans associations (VSLAs). The curriculum drew on adaptations from 'Journeys of Transformation' established by Promundo, CARE International and RWAMREC to involve Rwandan men as couples to support household activities, engage men in women's economic empowerment, and improve relationship dynamics (Slegh et al., 2013). The participatory sessions and take-home exercises with couples were designed to support couples to identify the causes and overlapping consequences of economic, emotional, physical, and sexual IPV, and build skills to manage triggers of IPV, such as communication and conflict resolution skills (Stern \& Nyitarunga, 2017). Approximately $25 \%$ of the 1680 individuals that completed the curriculum received further training by RWAMREC staff to become community activists to diffuse in their communities the positive uses of power and benefits of non-violent relationships. 
The programme also trained and supported approximately 40 opinion leaders (e.g religious leaders, local elected leaders, media personnel) per intervention sector to more effectively identify, prevent and respond to various types of IPV. Opinion leaders went through a two-week, condensed version of the couples curriculum training, with less emphasis on relationship skills and dynamics, and more on encouraging their active responses to IPV. In each sector, RWN implemented women's safe spaces which are staffed by facilitators, drawn from women living in the intervention communities, who were trained to provide opportunities for women to discuss experiences of IPV, educate women about their rights, and accompany women who wish to report abuse or seek health or social services. These facilitators are also supported to engage in wider level advocacy on women's rights and IPV prevention. The trainings with couples and opinion leaders and community activism drew on adaptations from the $S A S A$ ! IPV prevention programme in Uganda with its emphasis on negative and positive types and uses of power that can both underlie and prevent IPV, phasing according to Knowledge, Attitudes, Behaviours and Skills, supporting community members to engage in activism, and the involvement of diverse community stakeholders including local government and service providers to support an 'enabling environment' for change. The Rwandan Ministry of Gender and Family Promotion (MIGEPROF) is also critically on the Indashyikirwa programme advisory committee.

\section{Research Question}

Within the Rwandan context of rapidly shifting laws, policies and programmes to prevent IPV, which may not be grounded in social values and norms, it is warranted to 
understand community members' perceptions of the costs and consequences of IPV. There is a current gap around such insights, which are critical to inform the Indashyikirwa programme activities, monitoring and evaluation. This paper asks what are the perceived consequences of various forms of IPV (economic, emotional, physical, and sexual) among couples and opinion leaders that completed the Indashyikirwa trainings? The paper also seeks to unpack how beneficiaries' perceptions towards costs and consequences of IPV were influenced through the trainings, and highlights the implications of this for the ongoing programme and broader IPV prevention work.

\section{Methods}

The paper is based on research conducted in 3 Indashyikirwa intervention sectors (Rurembo Sector, Western Province; Gishari Sector, Eastern Province; and Gacaca Sector, Northern Province), which were purposefully selected to represent a diversity of environments including rural, urban and peri-urban locations. For the recruitment process, the first author informed staff from the Rwandan research company Laterite, which conducted the RCT component of the evaluation, and RWN staff members of recruitment criteria, aims, benefits, and risks of the study, so that these could be disseminated to potential participants. 30 baseline interviews were conducted in November 2015 with couples enrolled in but before having begun the Indashyikirwa couples curriculum. In each sector, 5 male and 5 female partners of couples were interviewed separately by same sex interviewers. Laterite staff members purposefully recruited couples, ensuring a diversity of formally and informally married couples. Laterite provided the qualitative researchers with couples' contact details after obtaining 
their consent to do so. The qualitative researchers than contacted these participants, and set up a time and location for conducting the interviews. The interviews asked partners of couples about their expectations of each other, how they resolve conflict, their communication skills and joint decision-making. If an experience of IPV was raised, couples were asked about the causes and implications of their last episode of IPV, whether they sought help afterwards and if so from whom. 28 midline interviews were conducted with couples immediately after their completion of the curriculum in May 2016 (due to one couple being lost to follow up) to assess their impressions of and impact of the curriculum. The baseline and midline interviews with partners of couples lasted approximately 1-1.5 hours.

Nine baseline interviews ( 3 per sector) were conducted with opinion leaders enrolled in and before completing the Indashyikirwa opinion leader module in November 2015. RWN staff members purposefully suggested a diversity of opinion leaders to include government leaders, members of anti-GBV committees or the National Women's Council 'and religious leaders. After obtaining the opinion leaders' consent to do so, RWN provided the qualitative researchers with their contact details. The qualitative researchers than contacted these opinion leaders, and set up a time and location for conducting these interviews. Interviews assessed whether opinion leaders have come into contact with couples having problems in their relationships, and the most common reasons that couples have conflict. Opinion leaders were also asked about gendered decision-making roles in families, how common IPV is in their communities and circumstances (if any) where they personally or community members believe this is 
justified. Six midline interviews were conducted with opinion leaders after 12 months, as 3 opinion leaders were lost to follow up due to leaving the programme or being replaced after local re-elections. These interviews assessed their impressions of the Indashyikirwa training and whether their involvement has influenced their work in IPV prevention and response. Baseline and midline interviews with opinion leaders lasted approximately 1 hour. All interviews were conducted at preferred locations deemed appropriate and private for participants.

A male Rwandan qualitative researcher external to the programme conducted the baseline and midline interviews with male partners of couples and some of the baseline opinion leader interviews. A female Rwandan qualitative researcher external to the programme conducted the baseline and midline interviews with female partners of couples, some of the baseline opinion leader interviews, and all the midline opinion leader interviews. All interviews were conducted in Kinyarwanda and audio recorded.

\section{Ethics}

Ethical approval to undertake the study was obtained from the Rwandan National Ethics Committee (RNEC) (REF: 340/RNEC/2015) and the National Institute of Statistics Rwanda (REF:0738/2015/10/NISR). Secondary approval was also obtained from the South Africa Medical Research Council (REF: EC033-10/2015) and from the London School of Hygiene and Tropical Medicine. Before each interview, information on the aims, risks and benefits of the research were provided and informed written consent was obtained from participants in adherence with the ethical approval guidelines given by the respective review boards. For participants who could not read or write, they were invited 
to bring a trusted individual to witness the consent form being read to them, and could opt to give their consent by thumbprint instead of by signature. All participants were paid 2000 Rwandan Francs (approximately USD 2.40) as a token of appreciation for their participation. All interviewees were informed of their guaranteed confidentiality and that no identifying information would be used in presentation of the data. Among couples, the researchers emphasized that nothing would be shared with their partners.

\section{Analysis}

The first author debriefed with the qualitative researchers after data collection to capture their initial impressions, non-verbal and contextual insights. These research summaries were used to inform the analysis. Using the audio files, the data was transcribed and translated verbatim into English by a language specialist and professional translator. After carefully reading the transcripts from couples and opinion leaders, the first author established a preliminary coding structure to analyse the data. Thematic analysis was conducted to uncover predominant themes in order to provide a rich, detailed and holistic account of the data (Braun \& Clarke, 2006). The thematic coding framework included themes purposefully elicited from the interviews, such as the various forms of IPV, and also allowed for the identification of grounded issues from the data. All of the transcripts were then analysed by the first author using this thematic coding framework with the assistance of NVIVO 11 software. An additional transcriber coded a small sub-set of the transcripts using NVIVO 11 and inter-coder agreement was found to be $95 \%$. The first author regularly presented the emerging findings to the Indashyikirwa senior programme staff at participatory workshops. At these workshops staff members offered their insights into the interpretation and analysis of the data, including around social norms and cultural 
values, to validate programmatic insights and to consider implications for the programme. The second author, the Indashyikirwa Programme Coordinator, actively participated at these workshops.

\section{Findings}

\section{Consequences of Various Forms of IPV}

The data reveals a depth of understanding of a range of consequences of diverse forms of IPV from hindering household economic growth, causing poor mental and physical health, to damaging intimate relationships. It is also apparent that awareness of the various forms of IPV and associated consequences was enhanced through the Indashyikirwa programme. Several opinion leaders and couples expressed the value of learning and identifying four types of IPV (economic, emotional, physical, sexual), the related causes and consequences through the trainings: "There are so many things that were done against us but we would not realize that we were being victims of violence." (FC04N, Midline) An opinion leader shared the value of the Indashyikirwa trainings for helping individuals better understand the consequences of IPV:

"These lessons are very good and the society would live better if people understood them. These issues disabled us and caused us poverty. " (OL01N, Midline)

Emphasizing how power inequalities underlie all forms of IPV appeared to be useful for raising awareness of the consequences of various types of IPV. The findings detail the perceived causes, forms and consequences of the four types of IPV, which were significant themes identified in the data, and is also how IPV was conceptualized and 
taught through the Indashyikirwa trainings. Moreover, doing so helps indicate the complexities of the varying impacts of diverse forms of IPV, as well as the overlapping causes and consequences.

\section{Physical IPV}

\section{Causes and Forms of Physical IPV}

Men's use of physical violence to discipline their wives was a common theme identified in the interviews. Several male and female partners of couples justified more 'minor' forms of men's use of physical IPV such as slapping or pushing, primarily for husbands to correct their wives' mistakes or for wives disobeying their husbands. A few opinion leaders also related this common societal perception: "the society thinks if you tell a woman something and she does not listen or understand you can slap her so that you wake her up." (OL01W, Baseline) Other triggers of men's use of physical IPV identified by couples and opinion leaders were actual or suspected extramarital affairs, wives neglecting household duties, disputes over household property and spending, and men's alcohol abuse. Some couples discussed the inevitability of a husband's use of physical IPV after a certain period of marriage to assert decision-making authority in the home. A few partners of couples indicated the perceived impossibility for women to use physical IPV given their inadequate strength compared to men, and due to expectations of wives to show humility and restraint:

\footnotetext{
"Imagine a woman beating her husband, Hahaha! Even if you were strong, how would you beat your husband? Even if you may be strong you would still be
} 
humble and you can't beat him." (FC01E, Baseline)

\section{Consequences of Physical IPV}

Even at the baseline interviews, there was strong consensus from couples and opinion leaders that men's use of physical IPV, which leads to injury or results in the need for medical care (said to be especially more likely when men were drunk), has severe potential consequences. These include hindering emotional and financial development of families, can lead to handicap or disability of survivors, husbands being prosecuted, which undermines family well-being since men are typically primary breadwinners, and households having to pay a fine for survivors to obtain healthcare. A few partners of couples noted how physical IPV undermines one's community status, especially for women. The physical and emotional impacts of ongoing physical IPV included wives living in constant fear of their husbands, forgetfulness, weight loss, sadness and anxiety, as emphasized by several female partners of couples:

"I would put rice on fire and get lost in my thoughts, thinking about my problems and I would not even realize that the rice took fire! I was always complaining and I had been emotionally affected! I had lost so much weight. I had been emotionally so affected that I would even leave money somewhere and I would forget where I have put it! Briefly I was not fine." (FC01N, Midline)

Several participants noted the importance of dialogue to solve conflict rather than IPV given such potential consequences, which was reinforced by the trainings. Indeed, there was strong consensus that physical IPV does not solve anything or change behaviours, and several participants used a Kinyarwanda proverb to illustrate this "Inkoni ivuna igufwa, ntabwo ivuna inges: A stick breaks the bone but does not break the habit." One 
female partner of a couple (FC02W, Baseline) remarked how physical IPV, rather than invoking women's respect for their partners, leads to disrespect and weakens the relationship. A male partner of a couple noted that physical IPV will not solve but rather exacerbate extramarital affairs:

"If you beat her when she has been unfaithful, this won't make her stop committing infidelity; it will instead push her to be more unfaithful because she will say, it all amounts to the same thing, he will beat me whether or not I have committed infidelity." (MC04E, Baseline)

A severe potential consequence of regular IPV identified by a female partner of a couple and one opinion leader was men's murder of their intimate partners. One male partner of a couple reported that learning about this severe consequence of IPV through the curriculum motivated his abandonment of physical IPV:

"They told me 'what you are doing is not good. You will kill your wife, and after killing her, you won't find another wife like her.' So, I understood that it is a shame and until now it has never happened again.” (MC05E, Midline)

After completing the curriculum, a few partners of couples reported learning about the harmful emotional and relational effects of more 'moderate' forms of physical IPV, including slapping, and how this was also a form of using 'power over': "It was just slapping her. My wife has always been patient. I used to come home drunk and I would argue with her but she could not tell me a word; but inside she was very hurt and very sad. She was carrying so much sorrow in her heart." (MC04N, Midline)

A few opinion leaders noted the expectation for community members to report 
incidences of physical IPV to local authorities to prevent its continuation and such consequences. They also discussed common public punishments by local authorities to prevent men's continued use of physical IPV:

"They bring him in front of the village members and charge him a small jerry can of umusururu. ${ }^{i i}$ They rebuke him and reprimand him, then they drink that umusururu. Sometimes they also give him advice, then let him g, but they give him a warning that if the same thing happens they will report him to the police. And we show him that what he is doing will cause negative consequences." (OL02W, Midline)

Several participants noted a significant reduction in men's use of physical IPV due to greater awareness of the negative consequences, which a few opinion leaders attributed to the government and community educational efforts, such as the parent's evening forums:

"Now that there is the parent's evening forum and that people have been taught about it, you see that it reduced and there is no man who beats his wife anymore. When there is a conflict between them, he takes her to other people and they educate her." (OL02E, Baseline) Acceptability of physical IPV was said to be shifting to the point where men could be mocked for using physical IPV given the related negative consequences:

"There is no legitimacy in beating a wife, it's rather destroying the household. And his friends can even laugh at him saying 'do you think that it is still acceptable to beat a wife?'” (FC01E, Baseline)

\section{Economic IPV}




\section{Causes and Forms of Economic IPV}

According to the Indashyikirwa trainings, economic IPV refers to any act that causes economic harms such as withholding family finances, stopping someone from getting or keeping a job, demanding to take or control someone's earnings, spending jointly earned family income without a spouse's consent, and preventing someone from owning property or inheriting land. Several participants relegated the commonality of men's use of economic IPV according to this definition. A persistent manifestation of economic IPV given was men denying their wives' access to property or inheritance of land, although it is their right under the law in Rwanda:

"Some couples even though they are legally married and signed for having equal rights on the property, you see a man saying: 'these are mine, that is my plot of land, that is my goat, that is my hen, that is my home.' He calls everything his up to the small things at home, regardless of the fact of being legally married. Sometimes you see that such a woman is living in misery where she cannot even get clothes." (OL01W, Midline)

Several female partners of couples reported that their partners regularly spend money on alcohol rather than using available funds to support daily living costs, which in this baseline interview was identified as a form of violence:

"The family may starve because he may earn his pay and buys alcoholic drinks for other people and he finishes all the money and comes home without money to provide food for the family. There is a man who doesn't beat you but who makes you suffer in a different way. If someone doesn't beat you but he doesn't provide food for you and he doesn't make you dress properly, that is also seen as 
violence." (FC04E, Baseline)

A few female partners of couples reported that their husbands could force them to give them their earnings, or prevent their access to household income. Several female partners appreciated learning that economic IPV was a violation of their rights through the curriculum. After discussing economic IPV through the curriculum, one opinion leader noted the importance of greater community awareness of forms and consequences of economic IPV: “Some people don't understand that financial violence is one of the types of violence. We still want to reinforce this." (OL01N, Midline)

\section{Consequences of Economic IPV}

At the point of baseline interviews, a few male and female partners of couples identified that economic IPV can trigger physical IPV and/or sexual IPV: "Sometimes he goes to the bar and if he earned some money he spends it all there. He can come being full whereas we didn't eat anything and he wants to have sexual intercourse, even if I might not be well. When you refuse to do it, that is when we can fight." (FC04E, Baseline) At both the baseline and midline interviews, several female partners of couples identified how their husbands preventing them from accessing earnings had a significant toll, including undermining their self-confidence and respect, and hindering their ability to

meet daily living costs. A few female couples also related the negative impact this has on children:

"Sometimes children are victims of violence because of their parents. When they were among other children who are clean and they don't have clothes sometimes I would spend a week without soap and he was refusing to buy this 
and you could see that our children were not clean." (FC04E, Midline)

A few opinion leaders and male partners of couples reported learning about the harmful relationship impacts of economic IPV, and the overlapping links with other forms of IPV through the curriculum:

"We have seen that not giving your wife the right to household property can be a cause of violence, especially when your wife realizes you squandered the family property she can rebuke you and when she does, you can commit the physical violence such as beating her or injuring her." (MC01W, Midline)

At the midline interviews, many men reflected how preventing their wives' access to resources, economic decision-making, or spending money on alcohol to the neglect of household needs, had significant financial consequences. The majority of male and female partners of couples appreciated learning about the household, economic, and relationship benefits of balancing and sharing economic resources and decision-making through the curriculum.

\section{Emotional IPV}

\section{Causes and Forms of Emotional IPV}

While acceptability of and frequency of physical IPV was generally said to be diminishing, a few opinion leaders and several partners of couples lamented the extent of men's regular use of emotional IPV. Common forms of men's emotional IPV identified included verbal abuse, shouting, belittlement, harassment, extreme jealousy, expelling women from their home, denying their association with others, and control of their 
movements. Some women reported threats of abandonment, which was more likely raised by informally married women as their rights to property or custody in case of separation is not guaranteed. One female partner of a couple related the emotional consequences of her husband's jealousy and identified this as violence after the training: "He would not allow me to go anywhere. When I had gone to the market, you know that sometimes one gets distracted by different things in the market. When I had taken long when I came back home he would argue with me telling me: 'that is not where you had gone. Go back there!' and that was bothering me and it made me sad, I felt that it was violence." (FC04E, Midline)

Although this was overall said to be much less common, a few male partners of couples reported experiencing emotional abuse by their intimate partners, primarily around being humiliated or criticized for not providing enough financially.

\section{Consequences of Emotional IPV}

Several partners of couples and opinion leaders reflected on the damage emotional IPV causes to relationships and individual well-being:

"I call it torture where someone makes you suffer for a long time and doesn't even beat you. If someone persecutes you every single night or if someone always tells you words that hurt you. We have at least four households out of ten, where you can find people who experience these problems; you cannot find signs that they have been beaten or injured but you find that the man is not proud of his wife or the wife is not proud of her husband. You can find that a wife wishes that her husband leaves so she is peaceful." (OL01E, Baseline) 
Several partners of couples and a few opinion leaders also identified the negative influence ongoing conflict among couples has on children, including on their mental health, well-being, and school performance:

"If parents are always in conflict, shouting, they are introducing a bad thing in the family: children don't get good education, they don't study well, children can't reach any development." (OL02W, Midline)

Despite these identified negative consequences, emotional IPV was generally a more normalized and justified form of IPV. Several partners of couples reported only identifying emotional IPV as a form of violence through the training, and how this has reduced as a result of such awareness:

"Sometimes you thought that as a woman your husband had to give you orders, or a husband could always harass you but we found out that it is not right and now it has changed." (FC03N, Midline)

Several male and female partners of couples reported the value of learning about the consequences of using abusive, harsh language through the couples curriculum, and the importance of rather using constructive and communicative dialogue:

"If you talk to her nicely she will respond to you nicely. We found out that verbal violence is on top to destroy households." (MC04E, Midline)

Identifying how verbal abuse was a form of using 'power over', including men over their wives, parents over their children, and opinion leaders in their own work, was said to be helpful for raising awareness of the consequences of such abuses of power. 


\section{Sexual IPV}

\section{Causes and Forms of Sexual IPV}

According to the Indashyikirwa trainings, sexual IPV could include forced sex/rape, marital rape, unwanted touching, grabbing sexual parts of the body, making someone do sexual things against their will, refusal to have protected sex, and defilement. Men's use of coerced sex against their wives was identified as a common phenomenon by partners of couples, although not readily identified as a form of violence, especially at the baseline interviews. Several partners of couples shared their perceptions that wives refusing sex may indicate infidelity or lack of sexual desire of their partner, leading to jealousy, conflict, and/or physical IPV, or husbands being more prone to seek outside sexual partners. Several female partners of couples reported their sense of responsibility to be readily available for sex, to avoid such negative consequences. A few female partners reported having learned this through religious marriage processes:

"We learned that especially during the religious marriage service, it is one of the lessons they teach the brides and the bridegrooms, because those are your responsibilities as a wife. If you refuse [sex] multiple times, you would be pushing him to become unfaithful to you. You can provoke problems for yourself by causing anger to him. Even if you may be angry you should endure and let him satisfy his sexual desire because he may become angrier than you are." (FC02E, Baseline)

A few male partners of couples also reported learning about their right to always have sex 
with their wives through religious institutions and messages, and one religious opinion leader (OL02W, Baseline) lamented this problematic perception. Several couples conceded that when men are drunk, they are more likely to force or coerce sex, and be less understanding of their wives' reasons to refuse sex. A few opinion leaders and couples noted that sexual IPV was more difficult to report to authorities for being highly stigmatized, and due to women's poor awareness of their rights to report marital rape: "She has sex unwillingly but thinks, instead of him beating me, let me accept. It's kind of forced sexual intercourse. But because they live together, she cannot file a case saying 'he has raped me.'” (MC03N, Baseline)

Yet, several couples and opinion leaders also indicated that wives' refusal of sex does not justify violence and indicated valid reasons for wives to not be interested in sex including being ill, menstruating, being tired from work and/or being responsible for all domestic duties. At the midline interviews, a few partners of couples noted how such reasons should be communicated to avoid disputes or coercion, which was emphasized through learning the value of open communication including about sexual readiness, needs and desires.

\section{Consequences of Sexual IPV}

Several partners of couples and a few opinion leaders discussed a wealth of harmful consequences of forced or coerced sex in intimate relationships including causing physical pain, weakness, sadness, and anxiety. A few female partners of couples reflected on the emotional damage and humiliation caused by their partners having pressured or forced them to perform sexual acts or engage in sexual positions they felt uncomfortable with. A few partners of couples shared their perceptions that forced or coerced sex is not 
satisfying, for both men and women. One female partner of a couple related how coerced sex diminishes love:

"When he does it [sex] by force, without preparing me, the consequence that I see is that your love progressively disappears due to misunderstandings." (FC04E, Baseline)

Indeed, a few female partners of couples relegated the negative relationship consequences of coerced sex, such as undermining communication:

"You feel that you are not in the mood for sex and then you refuse but he can get angry, and there are even those who can go for days without speaking to each other. But when you see that he becomes angry and there is no peace at home, you just accept and do it because it is one of your responsibilities." (FC03E, Baseline)

A few male partners of couples reported learning to identify sexual IPV and the related consequences through the curriculum, which was a shift from their perceived right to always have sex with their wives:

"I thought, my wife is mine, I married her; so, there is nothing which can prevent me from having sexual intercourse with her. But then, after receiving the lesson on sexual intercourse, we found out that she can sometimes be feeling unwell when you force her to have sexual intercourse, in that case you are committing violence." (MC04W, Midline)

A few female partners of couples valued learning through the curriculum their rights under the law to have consensual sexual relations with their husbands. Both male and 
female partners of couples reported the value of identifying through the curriculum that sexual IPV is broader than physically forcing sex, to include forms of sexual coercion such as through manipulation, emotional abuse, or to avoid conflict. At the midline interviews, the majority of couples reported an appreciation of learning about the benefits of consensual, equitable sex, as a powerful alternative to the harmful identified consequences of coerced sex.

\section{Discussion}

Participants were generally highly aware of the government's mandate to prevent physical IPV, and the associated consequences. There was generally less awareness of legal protections against marital rape or women's protection against certain forms of economic IPV, such as legally married women's rights to joint access of household property. All forms of IPV were said to be primarily committed by men, which has also been documented through Rwandan population based studies (Umubyeyi et al., 2014). Although several participants justified more minor forms of men's physical IPV, participants most readily identified consequences of physical IPV, which was generally perceived as highly discouraged, visible, and more likely subject to stigmatization and/or punishment. As a result, acceptance of men's use of physical IPV was said to be greatly reducing. The data suggests that the curriculum further raised couples' awareness of the harms of more 'minor' forms of physical IPV like slapping, through emphasizing how this was a form of 'power over,' and identifying the related consequences such as undermining love, respect, causing humiliation, and anxiety. The curriculum also helped couples identify how a pattern of physical IPV could become progressively worse to the 
point of severity such as murder, which helped shift some men's attitudes towards tolerance of physical IPV. Learning about the benefits of relationships without any physical violence was also helpful to undermine opinion leaders' and couples' tolerance of certain forms of physical IPV.

The baseline interviews with couples and opinion leaders suggest the commonality of women's experiences of economic IPV, despite the legal reforms in Rwanda meant to encourage women's economic empowerment and equal decisionmaking around household property. Other studies in Rwanda have found that even if formally married women provide written consent to sale or transfer of land due to the property law, they lack bargaining power around management, use and control of land, stay quiet to maintain peace in the household even if they disagree, and/or are coerced by their husbands to sign (Kaiser Hughes, Ndangiza, \& Ikirezi, 2016; Mwendwa Mechta et al., 2016). A major limitation of the Successions Law is that while legally married spouses must provide consent for the transfer of marital property, no provision requires spouses to share the profits associated with the transactions (Mwenda Mechta et al., 2016). Moreover, only legally married women are guaranteed rights to property and custody of their children in the case of divorce or separation from their spouse (Powley, 2007; Mwendwa Mechta et al., 2016). This limitation was raised as a concern by some participants, and could mean informally married women were especially prone to threats of abandonment. Many female partners of couples identified consequences of economic abuse, including how this was linked to other forms of IPV, and could exacerbate poverty and their inability to meet daily living needs. This may be especially salient with this 
study population given that the majority of couples trained were from vulnerable socioeconomic backgrounds. Many women were unaware that economic abuse was a form of IPV or a violation of their rights, which they appreciated learning through the curriculum. Men were generally less aware of the identification and consequences of economic IPV at baseline, although they learned about the harms of such IPV through the curriculum including poverty, undermining their wives, and having a negative impact on children. Couples and opinion leaders reported that learning the financial benefits and skills to balance economic decision-making was a powerful alternative to men holding all of the economic decision-making power.

Men's use of emotional IPV was said to be more common, typically less sanctioned and publicly visible than physical IPV, with less recognition of the harmful consequences. Although this was said to be less common for men than women, men were also said to suffer from emotional IPV. A population-based study in Rwanda similarly found that psychological IPV was the most common form of IPV targeting men (Umubyeyi et al., 2014). While several women identified negative consequences of experiencing emotional IPV including humiliation, disrespect, anxiety, and undermining the relationship, this was a more normalized form of abuse at the point of the baseline interviews. The majority of opinion leaders, male and female partners of couples learned to identify emotional abuse as a form of IPV and use of 'power over' through the trainings. It was helpful for opinion leaders and couples to learn how to manage triggers of conflict using constructive, positive communication rather than verbal abuse, shouting, harsh or critical language, especially given the identified consequences of using the later. 
Although many participants readily identified a variety of negative consequences of sexual IPV, the experiences of coerced sex were conflated by notions of women's responsibilities to submit to their husbands' sexual desires to avoid further negative consequences, and perceptions of men's rights to always have sex with their wives. The curriculum helped raise couples' awareness of a broader understanding of sexual coercion. Participants also suggested valid reasons for partners to not be interested in sex, and the curriculum helped emphasize how these, as well as sexual desires and needs should be openly communicated among partners. Women and men also reported learning about the negative consequences of sexual IPV, and the benefits of consensual, equitable sex through the curriculum.

The data speaks to the importance of supporting beneficiaries to not only understand the consequences of IPV, but also identify and manage triggers of IPV. One of the main triggers of all forms of IPV identified by couples and opinion leaders was men's alcohol abuse, which was also linked to harsher consequences, such as severe physical injuries. Thomson's (2015) analysis of the Rwanda 2005 and 2010 DHS similarly found that a husband who consumes alcohol often was a significant risk factor for IPV. Another study which interviewed more than 3600 Rwandan men and women aged 18-60 found that more than one in three men who drink beats their partner, while less than one in five who do not drink use violence (Slegh \& Kimonyo, 2010). This study suggested alcohol use is part of the construction of a dominant, powerful and often violent male role. Importantly, the Indashyikirwa couples curriculum had a session on 
skills to reduce alcohol use as a common trigger of violence, which was identified by the programme partners as critical to the context. Participants also reportedly benefitted from learning other skills to manage triggers of violence including constructive, open communication and joint decision-making.

\section{Limitations}

While it is valuable to have baseline and midline interviews with opinion leaders and couples to track shifting perceptions of IPV, it is important to note that the data from couples reflects their immediate perceptions after completing the curriculum, which may thus be socially biased. We tried to minimize such biases by emphasizing interviewers' external relation to the programme, and that couples' and opinion leaders' participation in the interviews would in no way affect their relationship with the programme. Endline interviews will be conducted with the same sub-set of couples and opinion leaders one year after their midline interviews to trace the longer-term influence of the programme and their processes of change. At endline, we will also be able to triangulate the findings with the RCT conducted with couples that completed the curriculum. More widespread and longitudinal data are warranted to better identify the consequences of IPV, especially areas with major gaps, such as the economic costs of IPV. Such insights could be especially salient in developing country contexts to support efforts for IPV prevention.

\section{Implications}

There was some indicated awareness of the overlapping links between the various forms of IPV, which indicates the importance of comprehensively addressing all types of IPV. There is evidence in Rwanda suggesting that economic violence where women and 
children are not provided for is often present in conjunction with other types of IPV (Mannell, Jackson, \& Umutoni, 2015; Umubyeyi et al., 2016). There have also been valid concerns that programmes that primarily focus on prevention of physical and sexual IPV may inadvertently shift men towards emotional IPV an alternative means of controlling their partners (Abramsky et al., 2016). The data emphasizes the need for the Indashyikirwa programme to build on the quite good understanding of the negative consequences of physical IPV, and support greater identification and awareness of consequences of less visible and scrutinized forms of violence, such as reportedly 'minor' forms of physical violence like slapping, emotional abuse, and sexual coercion in relationships. Highlighting the links and overlapping consequences between all forms of IPV, their relations to power imbalances, and the legal protection against various forms of IPV, appeared to be helpful for doing so. The findings also emphasize the need to address societal norms emphasizing the privacy of domestic sexual issues, and support couples with sexual communication skills, including reasons to refuse sex, to prevent sexual IPV. They also suggest the importance of engaging religious institutions and messaging, a powerful transmitter of social and gendered norms related to sexual relations and decision-making. Indashyikirwa is importantly planning to use materials for the community activism that draw on religious texts and messages to support gender equality, and will continue to engage with the trained religious opinion leaders in the activism activities.

Although the training supported beneficiaries to identify the harmful consequences of IPV, it concurrently supported an identification of the benefits of nonviolent, equitable relations, including relational, sexual, family and economic benefits. 
Several partners of couples related how all forms of IPV can diminish quality of relationships, including love and respect. Thus, promoting these relationship qualities and values may be important for supporting non-violence. Starmann et al. (2016) assessed processes of change among couples exposed to SASA! in Uganda, and suggested that SASA!'s focus on relationship values such as love, respect and trust supported reduced violence and improved relationship quality. The negative implications of IPV on children were also identified, and could provide a powerful platform to promote the value of nonviolent families. Indeed, positive, engaged modes of fatherhood have been found to be a powerful avenue to engage men in gender equality (Slegh \& Kimonyo, 2010).

Although significant work has taken place in Rwanda to raise awareness of the consequences of IPV, it is clear from this study and other perspectives (cf. Wallace, Haerpfer, \& Abbott, 2008), that the impressive GBV prevention efforts, laws and policies need to be better rooted in social values and norms. Although the long-term impact of the Indashyikirwa programme cannot yet be demonstrated, it promisingly seems that in addition to legal and policy reforms, offering safe spaces for stakeholders and couples to discuss, evaluate and modify perceived consequences of IPV is critical. However, difficult social contexts have been found to hinder the ability of small group education beneficiaries to maintain increased awareness and changed attitudes if their broader environment is not addressed (Campbell \& Cornish, 2010). Community mobilization strategies to prevent IPV are warranted as when significant masses of people change their beliefs and behaviors, social norms can change, which reinforces the attitude and behavior changes of individuals and families (Abramsky et al., 2012). Importantly, the 
Indashyikirwa curriculums are situated within community activism efforts to identify, raise awareness of the consequences of IPV, and promote the benefits of non-violence among the broader community and with key stakeholders.

\section{References}

Abramsky, T., Devries, K., Kiss, L., Francisco, L., Nakuti, J., Musuya, T., ... Watts, C. (2012). A community mobilisation intervention to prevent violence against women and reduce HIV/AIDS risk in Kampala, Uganda (the SASA! Study): study protocol for a cluster randomised controlled trial. Trials, 13, 96. doi:10.1186/1745-6215-13-96

Alio, A. P., Clayton, H. B., Garba, M., Mbah, A. K., Daley, E., \& Salihu, H. M. (2010). Spousal concordance in attitudes toward violence and reported physical abuse in african couples. Journal of Interpersonal Violence, 26(14), 2790-2810.

doi:10.1177/0886260510390951

Braun, V., \& Clarke, V. (2006). Using thematic analysis in psychology. Qualitative Research in Psychology, 3(2), 77-101. doi:10.1191/1478088706qp063oa

Buzawa, E. S., \& Buzawa, C. G. (2013). What does research suggest are the primary Risk and protective factors for intimate partner violence (IPV) and what is the role of economic factors? Journal of Policy Analysis and Management, 32(1), 128-137. doi:10.1002/pam.21668

Campbell, C., \& Cornish, F. (2010). Towards a "fourth generation" of approaches to HIV/AIDS management: creating contexts for effective community mobilisation. AIDS Care, 22(sup2), 1569-1579. doi:10.1080/09540121.2010.525812

Campbell, C., Scott, K., Nhamo, M., Nyamukapa, C., Madanhire, C., Skovdal, M., .. . Gregson, S. (2013). Social capital and HIV competent communities: The role of 
community groups in managing HIV/AIDS in rural Zimbabwe. AIDS Care, 25(Suppl 1), S114-S122. doi:10.1080/09540121.2012.748170

Debusscher, P., \& Ansoms, A. (2013). Gender equality policies in Rwanda: Public relations or real transformations? Development and Change, 44(5), 1111-1134.

doi:10.1111/dech.12052

Devries, K. M., Mak, J., Garcia-Moreno, C., Petzold, M., Child, J., Falder, G., ... Watts, C. H. (2013). The global prevalence of intimate partner violence against women. Science 340 (6140):1527-1528. doi: 10.1126/science.1240937.

Devries, K. M., Child, J. C., Bacchus, L. J., Mak, J., Falder, G., Graham, K., . . Heise, L. (2014). Intimate partner violence victimization and alcohol consumption in women: a systematic review and meta-analysis. Addiction, 109(3), 379-391. doi:10.1111/add.12393

Ellsberg, M., Jansen, H., Heise, L., Watts, C., \& Garcia-Moreno, C. Intimate partner violence and women's physical and mental health in the WHO multi-country study on women's health and domestic violence: an observational study. (2008). The Lancet, 371(9619), 1165-1172. doi:10.1016/S0140-6736(08)60522-X

Friere, P. (1973). Education as the practice of freedom in education for critical consciousness. New York Continuum.

Goodwin, S., Chandler, D., \& Meisel, J. (2004). Violence against women: The role of welfare reform, final report. US National Institute of Justice.

Hebert, L. A. (2015). "Women run the show"?: Gender violence reform and the "stretching" of human rights in Rwanda. Journal of Human Rights, 14(1), 23-40. doi: $10.1080 / 14754835.2014 .886944$ 
Jewkes, R., Nduna, M., Levin, J., Jama, N., Dunkle, K., Puren, A., \& Duvvury, N. (2008). Impact of stepping stones on incidence of HIV and HSV-2 and sexual behaviour in rural South Africa: cluster randomised controlled trial. BMJ, 337, a506. doi:10.1136/bmj.a506

Kaiser Hughes, A., Ndangiza, M., \& Ikirezi, M. (2016). The rights of women in de facto unions to land and property. USAID Land Project, Kigali, Rwanda.

Kubai, A., \& Ahlberg, B. M. (2013). Making and unmaking ethnicities in the Rwandan context: implication for gender-based violence, health, and wellbeing of women. Ethnicity \& Health, 18(5), 469-482. doi:10.1080/13557858.2013.832012

Mannell, J., Jackson, S., \& Umutoni, A. (2015). Women's responses to intimate partner violence in Rwanda: Rethinking agency in constrained social contexts. Global Public Health, 1-17. doi:10.1080/17441692.2015.1013050

Mwendwa Mechta, S., Buscagli, I., Bikesha, D., \& Routte, J. (2016). Decision-making and joint control rights over land in Rwanda. Kigali, International Alert.

National Institute of Statistics Rwanda. (2016). Demographic Health Survey 2014/2015Final Report. Kigali, Rwanda.

Powley, E. (2007). Rwanda: The impact of women legislators on policy outcomes affecting children and families. State of the World's Children 2007 Background Paper, UNICEF.

Rani, M., Bonu, S., \& Diop-Sidibe, N. (2004). An empirical investigation of attitudes towards wife-beating among men and women in seven sub-Saharan African countries. African Journal of Reproductive Health, 8(3), 116-136. 
Silverman, J. G., Decker, M. R., Saggurti, N., Balaiah, D., \& Raj, A. (2008). Intimate partner violence and HIV infection among married Indian women. JAMA, 300(6), 703710. doi:10.1001/jama.300.6.703

Slegh, H., Barker, G., Kimonyo, A., Ndolimana, P., \& Bannerman, M. (2013). 'I can do women's work': reflections on engaging men as allies in women's economic empowerment in Rwanda. Gender \& Development, 21(1), 15-30.

doi:10.1080/13552074.2013.767495

Slegh, H., \& Kimonyo, A. (2010). Masculinity and Gender Based Violence in Rwanda: Experiences and perceptions of men and women. RWAMREC, MenEngage, ICRW.

Sommers, M. (2012). Stuck: Rwandan youth and the struggle for adulthood Athens, GA: University of Georgia Press.

Starmann, E., Collumbien, M., Kyegombe, N., Devries, K., Michau, L., Musuya, T., Watts, C., \& Heise, L. (2016). Exploring couples' process of change in the context of SASA!, a violence against women and HIV prevention intervention in Uganda. Prevention Science. doi: 10.1007/s11121-016-0716-6.

Stern, E., \& Nyiratunga, R. (2017). A process review of the Indashyikirwa couples curriculum to prevent intimate partner violence and support healthy, equitable relationships in Rwanda. Social Sciences, 6 (63). doi: 10.3390/socsci6020063

Swanberg, J., Logan, T.K., Macke, J. (2005). Intimate partner violence, employment and the workplace: Consequences and future Directions. Trauma, Violence \& Abuse, 6(4), 286-312.

Thomson, D., Bah, A., Rubanzana, W., \& Mutesa, L. (2015). Correlates of intimate partner violence against women during a time of rapid social transition in Rwanda: Analysis of the 2005 and 2010 Demographic and Health Surveys. BMC Women's Health 
$15(1)$.

Umubyeyi, A., Mogren, I., Ntaganira, J., \& Krantz, G. (2014). Women are considerably more exposed to intimate partner violence than men in Rwanda: results from a population-based, cross-sectional study. BMC Womens Health, 14, 99.

doi:10.1186/1472-6874-14-99

Umubyeyi, A., Persson, M., Mogren, I., \& Krantz, G. (2016). Gender inequality prevents abused women from seeking care despite protection given in gender-based violence legislation: A Qualitative Study from Rwanda. PLoS One, 11(5), e0154540. doi:10.1371/journal.pone. 0154540

Uwineza, P., \& Pearson, E. (2009). Sustaining women's gains in Rwanda: The influence of indigenous culture and post-genocide politics. Institute for Inclusive Security.

Wallace, C., Haerpfer, C., \& Abbott, P. (2008). Women in Rwandan Politics and Society. International Journal of Sociology, 38(4), 111-125. doi: 10.2753/IJS0020-7659380406

\section{Footnotes}

\footnotetext{
${ }^{i}$ The National Women's Council in Rwanda, which was established in 1996, is a social forum where girls and women pool their ideas to solve their own problems and to participate in the development of the country. The council has structures from the grassroots up to the national level, and provides for women's participation in local governance at all administrative levels

ii A Rwandan alcoholic drink made with sorghum
}

Table 1: Demographic Information of Opinion Leaders Interviewed

\begin{tabular}{|l|l|l|l|}
\hline ID & Role & Gender & Province \\
\hline OL01N & $\begin{array}{l}\text { Opinion Leader (Religious } \\
\text { leader) }\end{array}$ & Male & Northern Province \\
\hline OL02N & $\begin{array}{l}\text { Opinion Leader } \\
\text { (Government leader) }\end{array}$ & Male & Northern Province \\
\hline
\end{tabular}




\begin{tabular}{|l|l|l|l|}
\hline OL03N & $\begin{array}{l}\text { Opinon Leader (GBV } \\
\text { Committee and Cell } \\
\text { Mediator ) }\end{array}$ & Male & Northern Province \\
\hline OL01W & $\begin{array}{l}\text { Opinion Leader (GBV } \\
\text { Committee) }\end{array}$ & Female & Western Province \\
\hline OL02W & $\begin{array}{l}\text { Opinion Leader (Religious } \\
\text { Leader) }\end{array}$ & Male & Western Province \\
\hline OL03W & $\begin{array}{l}\text { Opinion Leader } \\
\text { (Government Leader) }\end{array}$ & Male & Western Province \\
\hline OL01E & $\begin{array}{l}\text { Opinion Leader } \\
\text { (Government Leader) }\end{array}$ & Male & Eastern Province \\
\hline OL02E & $\begin{array}{l}\text { Opinion Leader (CNF } \\
\text { Member) }\end{array}$ & Female & Eastern Province \\
\hline OL03E & $\begin{array}{l}\text { Opinion Leader } \\
\text { (Government Leader) }\end{array}$ & Male & Eastern Province \\
\hline
\end{tabular}

Table 2: Demographic Information of Partners of Couples Interviewed

\begin{tabular}{|c|c|c|c|c|}
\hline ID & Gender & $\begin{array}{l}\text { Age (at time of } \\
\text { midline interview) }\end{array}$ & Province & Marital Status \\
\hline FC01W & Female & 29 & $\begin{array}{l}\text { Western } \\
\text { Province }\end{array}$ & $\begin{array}{l}\text { Informally } \\
\text { Married }\end{array}$ \\
\hline $\mathrm{MC} 01 \mathrm{~W}$ & Male & 38 & $\begin{array}{l}\text { Northern } \\
\text { Province }\end{array}$ & $\begin{array}{l}\text { Informally } \\
\text { Married }\end{array}$ \\
\hline FC02W & Female & 29 & $\begin{array}{l}\text { Western } \\
\text { Province }\end{array}$ & Formally Married \\
\hline $\mathrm{MC} 02 \mathrm{~W}$ & Male & 30 & $\begin{array}{l}\text { Western } \\
\text { Province }\end{array}$ & Formally Married \\
\hline FC03W & Female & 37 & $\begin{array}{l}\text { Western } \\
\text { Province }\end{array}$ & Formally Married \\
\hline $\mathrm{MC} 03 \mathrm{~W}$ & Male & 37 & $\begin{array}{l}\text { Western } \\
\text { Province }\end{array}$ & Formally Married \\
\hline FC04W & Female & 33 & $\begin{array}{l}\text { Western } \\
\text { Province }\end{array}$ & $\begin{array}{l}\text { Informally } \\
\text { Married }\end{array}$ \\
\hline $\mathrm{MC} 04 \mathrm{~W}$ & Male & 32 & $\begin{array}{l}\text { Western } \\
\text { Province }\end{array}$ & $\begin{array}{l}\text { Informally } \\
\text { Married }\end{array}$ \\
\hline FC05W & Female & 35 & $\begin{array}{l}\text { Western } \\
\text { Province }\end{array}$ & Formally Married \\
\hline $\mathrm{MC} 05 \mathrm{~W}$ & Male & 33 & $\begin{array}{l}\text { Western } \\
\text { Province }\end{array}$ & Formally Married \\
\hline$\overline{\mathrm{FC} 01 \mathrm{~N}}$ & Female & 27 & $\begin{array}{l}\text { Northern } \\
\text { Province }\end{array}$ & Formally Married \\
\hline $\mathrm{MC} 01 \mathrm{~N}$ & Male & 36 & $\begin{array}{l}\text { Northern } \\
\text { Province }\end{array}$ & Formally Married \\
\hline FC02N & Female & 21 & $\begin{array}{l}\text { Northern } \\
\text { Province }\end{array}$ & $\begin{array}{l}\text { Informally } \\
\text { Married }\end{array}$ \\
\hline $\mathrm{MC} 02 \mathrm{~N}$ & Male & 23 & $\begin{array}{l}\text { Northern } \\
\text { Province }\end{array}$ & $\begin{array}{l}\text { Informally } \\
\text { Married }\end{array}$ \\
\hline
\end{tabular}




\begin{tabular}{|c|c|c|c|c|}
\hline FC03N & Female & 28 & $\begin{array}{l}\text { Northern } \\
\text { Province }\end{array}$ & $\begin{array}{l}\text { Informally } \\
\text { Married }\end{array}$ \\
\hline $\mathrm{MC} 03 \mathrm{~N}$ & Male & 30 & $\begin{array}{l}\text { Northern } \\
\text { Province }\end{array}$ & $\begin{array}{l}\text { Informally } \\
\text { married }\end{array}$ \\
\hline FC04N & Female & 27 & $\begin{array}{l}\text { Northern } \\
\text { Province }\end{array}$ & Formally Married \\
\hline $\mathrm{MC} 04 \mathrm{~N}$ & Male & 29 & $\begin{array}{l}\text { Northern } \\
\text { Province }\end{array}$ & Formally Married \\
\hline FC05N & Female & 45 & $\begin{array}{l}\text { Northern } \\
\text { Province }\end{array}$ & Formally Married \\
\hline $\mathrm{MC} 05 \mathrm{~N}$ & Male & 45 & $\begin{array}{l}\text { Northern } \\
\text { Province }\end{array}$ & Formally Married \\
\hline FC01E & Female & 45 & $\begin{array}{l}\text { Eastern } \\
\text { Province }\end{array}$ & $\begin{array}{l}\text { Informally } \\
\text { Married }\end{array}$ \\
\hline MC01E & Male & 42 & $\begin{array}{l}\text { Eastern } \\
\text { Province }\end{array}$ & $\begin{array}{l}\text { Informally } \\
\text { Married }\end{array}$ \\
\hline FC02E & Female & 27 & $\begin{array}{l}\text { Eastern } \\
\text { Province }\end{array}$ & $\begin{array}{l}\text { Informally } \\
\text { Married }\end{array}$ \\
\hline MC02E & Male & 29 & $\begin{array}{l}\text { Eastern } \\
\text { Province }\end{array}$ & $\begin{array}{l}\text { Informally } \\
\text { Married }\end{array}$ \\
\hline FC03E & Female & 24 & $\begin{array}{l}\text { Eastern } \\
\text { Province }\end{array}$ & Formally Married \\
\hline MC03E & Male & 37 & $\begin{array}{l}\text { Eastern } \\
\text { Province }\end{array}$ & Formally Married \\
\hline FC04E & Female & 30 & $\begin{array}{l}\text { Eastern } \\
\text { Province }\end{array}$ & $\begin{array}{l}\text { Formally } \\
\text { Marrierd }\end{array}$ \\
\hline MC04E & Male & 32 & $\begin{array}{l}\text { Eastern } \\
\text { Province }\end{array}$ & Formally Married \\
\hline FC05E & Female & 36 & $\begin{array}{l}\text { Eastern } \\
\text { Province }\end{array}$ & $\begin{array}{l}\text { Informally } \\
\text { Married }\end{array}$ \\
\hline MC05E & Male & 38 & $\begin{array}{l}\text { Eastern } \\
\text { Province }\end{array}$ & $\begin{array}{l}\text { Informally } \\
\text { Married }\end{array}$ \\
\hline
\end{tabular}

